2. O Brasil e as fronteiras latino-americanas: diálogo, presença/ausência 


\title{
As posições do discurso latino-americano
}

\author{
Myriam Ávila I UFMG/CNPq
}

\begin{abstract}
Resumo: Este artigo revê conceitos como hibridismo, entrelugar e dupla consciência, fazendo consideraçôes sobre o seu rendimento teórico no discurso latino-americano.

Palavras-chave: Latino-americanismo, Silviano Santiago, Alberto Moreiras.
\end{abstract}

\begin{abstract}
As colocações teóricas dificilmente podem prescindir de uma representação espacial. O pensamento abstrato parece necessitar desse apoio representacional para se articular de forma compreensível. Num outro contexto, Kant aponta, na Crítica da razão pura, para o fato de que o tempo e o espaço são condições a priori da sensibilidade, modos de ir à realidade ("Estética transcendental", parágrafos 2 a 8 , passim).${ }^{1}$ A partir do reconhecimento dessa dependência, pode-se afirmar que o discurso latino-americano postula suas posições (a própria palavra já remete à espacialização) relacionalmente, a partir de seu deslocamento com relação a um centro. Termos como "periférico", "entrelugar" e mesmo a "mirada estrábica" de Ricardo Piglia têm como pressuposto esse deslocamento.

Pretendo explorar aqui duas possibilidades de representação posicional e tentar pensar a especificidade de cada uma quando aplicadas à América
\end{abstract}

1. Agradeço a Rodrigo Duarte pela indicação desse trecho. 
Latina, tomando como exemplo textos de dois importantes teóricos contemporâneos de sua literatura e cultura: Silviano Santiago e Alberto Moreiras. Os dois modelos de representação a que me refiro são o par binário 0-1, base do pensamento digital que domina o mundo contemporâneo e a tríade 0-1-2 que Julia Kristeva apresenta no seu livro de 1969, Introdução à semanálise. O par 0-1 corresponde às oposições vazio/cheio, ausência/presença, negação/afirmação, não marcado/marcado. A desconstrução teórica do binarismo, operada pelos pós-estruturalistas (especialmente Derrida) como parte de seu "programa" (de base heideggeriana) de desmonte da razão iluminista, teve profunda influência sobre o pensamento latino-americano da segunda metade do século XX, que não via na oposição uma saída válida da hierarquia centro-periferia, cultural e historicamente construída desde os primeiros tempos da colonização europeia.

"Condenados" pela colonização e o extermínio dos povos nativos a adotar a língua - vale dizer, sempre, os valores - do colonizador, vimo-nos falando pela boca desse outro que era o Um, relegados à condição de secundidade e à cópia. Já o uso dessa língua nos impediria, portanto, de tomar a negação como postura crítica, o que fatalmente nos reduziria ao silêncio. ${ }^{2}$

O primeiro impulso de uma teoria nascida nos trópicos é, deste modo, o de evitar as posições drásticas do não e do sim e buscar na mistura a sua "coloração" própria. Toma-se assim o hibridismo - mais explicitamente, nas primeiras teorias latino-americanas relevantes, a mestiçagem - como a condição específica do nosso discurso e de nossa representação para o Outro. A intenção de estabelecer esse lugar próprio e pensar a partir dele não constituiu, entretanto, uma garantia contra o uso autoritário dessa autoimagem apaziguadora. Alberto Moreiras destaca os usos políticos da ideia de hibridismo ${ }^{3}$ em seu livro A exaustão da diferença (2001), ligando-a ao estado nacional-populista. Embora o conceito só tenha sido sistematizado na década de 1980 por Néstor García Canclini, já num contexto de globalização, Moreiras vê aí uma continuidade ideológica potencialmente perigosa. Canclini não teria sabido corrigir esse desvio, que tenderia a naturalizar a exclusão do subalterno, e que identifica, no limite, hibridismo com domesticação.

2. Numa perspectiva semelhante, Gaiatri Spivak formulou a questão: "O subalterno pode falar?".

3. No Brasil, a construção teórica de Gilberto Freyre, mesmo que à revelia do autor, foi incorporada pela ditadura Vargas, como fundamentação de um nacionalismo ideologicamente útil. 
Em outros contextos, extra-americanos, o hibridismo tem sido acolhido com interesse como um conceito capaz de promover a inclusão e a diversidade. ${ }^{4}$ No nosso continente, entretanto, esse termo resvala inevitavelmente para a ideia de mesclagem étnica que, por um hábito já naturalizado de pensamento, tende a abrigar um esforço de apagamento do diferente, por sua crescente dissolução no igual. Assim, a ideia de negociação, que pressupõe dois sujeitos atuando em condições paritárias, dá lugar à "descoloração" étnica numa mistura em que o eterno subalterno aparece como o verniz exótico que torna atrativo um discurso hegemônico desgastado. Peter Burke, que publicou no Brasil um livro intítulado Hibridismo cultural, mostra-se consciente dessa questão, em entrevista, ${ }^{5}$ ao preferir “a metáfora da 'tradução' de culturas (...), pois ela expressa bem a idéia de que as conseqüências culturais de encontros não são automáticas, que as pessoas têm de trabalhar para adaptar itens de uma cultura para outra".

Se o hibridismo pode se tornar um disfarce ideológico do próprio discurso da dominação, uma outra formulação teórica a partir do par 0-1 evita conciliar seus dois polos através da ideia de mescla e fornece um poderoso operador à reflexão sobre a cultura e a literatura latino-americanas. Trata-se do conceito de "entre-lugar", cunhado por Silviano Santiago em 1978, segundo o qual a enunciação latino-americana ocuparia um lugar incerto entre duas posições discursivas, ou entre $a$ posição dominante e sua negação pura. Embora Santiago também parta da idéia de mestiçagem, ${ }^{6}$ avança com relação à formulação tradicional da fusão de culturas ao aproximar os conceitos de unidade e pureza como os dois pilares do discurso de dominação: "Na álgebra do conquistador, a unidade é a única medida que conta,"7 comenta ele. E propõe como a tarefa primordial de um novo discurso crítico - o da América Latina - a destruição sistemática desses dois conceitos. O entrelugar não significa, portanto, a soma mestiça de 0 e 1 , mas uma posição clandestina e indeterminada que oscila "Entre o sacrifício e o jogo, entre a prisão e a transgressão, entre a submissão ao código e a agressão, entre a obediência e a rebelião, entre a assimilação e a expressão (...).,8

4. Ver BURKE. Hibridismo cultural.

5. MACHADO. Hibridismo cultural de Peter Burke (24/01/04).

6. SANTIAGO. Uma literatura nos trópicos, p. 15.

7. SANTIAgO. Uma literatura nos trópicos, p. 14.

8. SANTIAGo. Uma literatura nos trópicos, p. 26. 
Uma outra figuração do olhar crítico que ocorre no pensamento de Silviano Santiago pode ser usada para se fazer a transição entre os modelos posicionais diádico e triádico: a da dobradiça. Tendo primeiro utilizado o termo para nomear seu processo de estruturação de personagens no romance Stella Manhattan, Santiago dá margem a que se compreenda a dobradiça como a possibilidade de ocupar diferentes posições simultaneamente, sem que uma delas se apresente como a verdadeira e sem que haja impostura, e sim fragmentação, nesse desdobramento. Deixando de lado o princípio de identidade, torna-se possível, à revelia da experiência empírica que costuma guiar nossas operações mentais, propor que o mesmo objeto (teórico) ocupe dois lugares ao mesmo tempo.

Julia Kristeva, elaborando sobre uma colocação de Saussure, ${ }^{9}$ postula a ambivalência como propriedade da linguagem poética e "único procedimento que permite ao escritor entrar na história”. ${ }^{10}$ A articulação dupla permitiria pensar uma prática linguística capaz de escapar à posição 1, que ela identifica com "Deus, a lei, a definição". Toda narrativa que obedece à lógica digital (0-1) é, segundo ela, dogmática. O abandono dessa lógica, e sua reposição pela lógica poética (0-2), realizar-se-ia com êxito no discurso do carnaval, ${ }^{11}$ tipicamente transgressor. Mesmo se Kristeva não contempla diretamente em seu texto a enunciação do subalterno, a ideia de uma "relação de termos oposicionais não-exclusivos"12 se aplica de forma interessante às necessidades dessa enunciação. A ambivalência impede a prevalência do discurso da unidade, alvo central do pensamento social latino-americano, segundo Silviano Santiago.

Uma formulação bem anterior da articulação dupla como postura possível diante da dominação já fora dada por W.E.B. DuBois em 1903. Militante afro-americano, um dos precursores do movimento negro americano, DuBois refere-se à consciência do negro como clivada entre duas experiências: a identificação com sua raça pela opressão comum e a identificação com seu tempo - a modernidade - via valores construídos pelo opressor de origem europeia. Alberto Moreiras vai buscar no conceito de "dupla consciência" de DuBois uma alternativa contra as falácias do discurso do hibridismo (ele não se refere textualmente ao conceito de

9. A noção de paragrama exposta em Anagrammes.

10. KRISTEVA. Introdução à semanálise, p. 68.

11. A referência é à carnavalização como descrita por Bakhtin.

12. KRISTEVA. Introdução à semanálise, p .70. 
"entre-lugar"). Usando alternativamente as expressões "registro duplo" e "dupla inscrição", Moreiras desloca para o espaço latino-americano a vivência dobradiça do (sub)cidadão americano de origem africana.

Assim como Paul Gilroy, ${ }^{13}$ retomando o texto de DuBois, propõe que a consciência negra se dá em uma agenda política dupla, também Moreiras reinvindica para o latino-americanismo uma "política da plenitude" e uma "política da transfiguração". Gilroy define a "política da plenitude" "14 como uma prática dos descendentes de escravos em sua demanda de que a sociedade civil burguesa cumpra as promessas de sua própria retórica. Já a "política da transfiguração" partilha da ordem do desejo, invocando referências utópicas que se expressam prefigurativamente no canto, na dança, na performance, nos signos entrecortados e suplementados por sons inarticulados que são frequentes na cultura negra. No discurso latino-americano, tratar-se-ia de, ao lado de uma política de atuação no real que o fizesse ecoar de forma efetiva no conjunto dos discursos, preservar um horizonte de mudança radical ainda não compatível com as atuais condições de luta. Para dar um exemplo bastante rasteiro, seria como se um fervoroso socialista mantivesse sua utopia de um mundo perfeitamente igualitário enquanto luta, no dia a dia, pela aquisição de pequenos ganhos sociais dentro do sistema capitalista.

A proposta escapa um pouco ao nosso escopo. A literatura e os estudos culturais que a tomam como objeto travam suas lutas em um campo simbólico, ao passo que o movimento negro tem objetivos bastante pragmáticos em vista. Se transpusermos os dois níveis políticos mencionados para a área do discurso teórico, veremos a questão se alterar para as lutas travadas no interior da esfera dos discursos, ou seja, a luta pelo espaço e ressonância de um determinado discurso - o latino-americanista - frente aos demais. O nível utópico serviria então de rótulo legitimador para os ganhos políticos mais práticos da ordem da visibilidade pública. Não é à toa que Moreiras, no fim de seu texto, se volta para o mundo acadêmico, lugar de proliferação e disputa de discursos na atualidade:

Quer seja rebelde ou historicamente constituído, o latino-americanismo tem um lugar subordinado no discurso universitário: existe também uma política hegemônica em jogo nesse campo. Como agir a partir de uma

13. GILROY. The black Atlantic: modernity and double consciousness.

14. Uma tradução mais próxima do original "politics of fulfilment" seria "política da realização". 
posição de força se o que sempre acontece é a submissão às diretrizes do discurso universitário (...) ${ }^{15}$

Moreiras conclui que a responsabilidade última do latino-americanista é "forçar nosso pensamento até seus limites institucionais". ${ }^{16}$ Parece pouco para o esforço que se fez de desconstruir as ideia de hibridismo, mestiçagem, fusão intercultural e unidade. Os "limites institucionais", até onde devemos "forçar nosso pensamento", amesquinham a questão em jogo, fazendo soar a inscrição dupla como mera duplicidade (aqui, no sentido moral). Lembrando a velha pretensão de "combater o sistema de dentro do sistema", no fundo seria uma tentativa de empoderamento (empowerment) totalmente obediente às condições dadas.

O uso propositivo da dupla consciência, ou da dupla articulação esconde, portanto, um perigo: o de, uma vez resguardada a meta radical de uma agência sob a forma de "transfiguração" - algo que se daria em um futuro nunca à vista - permitir que nos contentemos com a micropolítica do cotidiano, em busca da posição mais confortável possível. Em lugar de instalar o desconforto, sem o qual a teoria não vale a pena ou se transforma em mero jogo de poder, como aquele a que se refere Moreiras, eis-nos disputando degraus no interior de um discurso já instalado.

Por outro lado, o uso constatativo do registro duplo é de imenso interesse. Lembremo-nos que o conceito ocorreu a DuBois não como construto $a$ priori, mas como resultado de uma vivência empírica que, a cada vez, exigia seu posicionamento a partir de uma de suas inscrições: a de intelectual de uma potência econômica plenamente identificado com seu tempo e a de minoria oprimida, excluída do imaginário da cultura em que se encontra imerso. Filho de uma cultura e ponto cego dessa mesma cultura. A todos nós latino-americanos, que somos obrigados a dizer com Borges que a cultura europeia "nos pertence toda", já que esse pertencimento não se dá como pressuposto, a sensação é conhecida. A noção de ser um Outro na cultura mesma em que nos espelhamos fatalmente nos leva a viver uma consciência dupla. A constatação dessa ambivalência de base garante por si só uma perspectiva crítica com relação a cada uma dessas identificações. Vale dizer: a questão da identidade passa a ser colocada em termos de identificação.

15. MOREIRAS. A exaustão da diferença, p. 354.

16. MOREIRAS. A exaustão da diferença, p. 354. 
Ou, como defini em outro texto, ${ }^{17}$ torna-se possível ver a cultura como "conjunto de bens de identificação de um grupo", podendo esse grupo coincidir com populações inteiras e, no limite, com a própria humanidade.

Outra vantagem da ambivalência ou lógica do 0-2 é esquivar-se por definição ao lugar da lei (posição 1) sem querer estabelecer outro lugar normativo alternativo. Escapando à hierarquia que a proposta de uma "política do real" e uma "política do ideal" não pode deixar de evocar, a lógica da ambivalência desafia o princípio de identidade que funda o discurso positivista, claramente improdutivo diante de uma realidade complexa. O resultado é um pensamento que não recua diante da contradição e do paradoxo, mas, ao contrário, progride por paradoxos. Sem a obrigação de atender ao cânone da causalidade, pode-se acolher mais de uma perspectiva sem buscar conciliá-las. A flexibilização dos processos mentais é uma decorrência vantajosa.

Moreiras entende que diversos conceitos-guia do latino-americanismo necessitam um conceito suplementar que lhes sirva de corretivo, diante do risco de se cair de novo em uma enunciação hegemônica (especificamente, se levarmos em conta a história da América Latina, o vício do populismo). Seguindo esse mesmo raciocínio, podemos propor como corretivo à articulação dupla a destruição sistemática do ideal da unidade, como já queria Silviano Santiago. A ideia de unidade se coloca como meta do discurso lógico sob as formas da coesão e da coerência. No nível ideológico, essa meta chega a irmanar esquerda e direita, ambas conclamando à união. Silviano chama a atenção para a tendência hegemônica que o "grand récit" da unificação carrega consigo.

Em termos do discurso latino-americano, entendo como impulso unificador a tentativa de fazer prevalecer uma única leitura teórica da América Latina. Se mantivermos válidos os diversos conceitos que correspondem aos vários esforços para compreender e descrever esse espaço discursivo, se considerarmos o paradoxo uma instância produtiva, e não impeditiva, se, por fim, desconstruirmos as apropriações que o poder político e econômico faz desses mesmos conceitos, teremos uma leitura mais rica e proveitosa das diferenças irreconciliáveis que formam o espaço simbólico latino-americano.

Wander Melo Miranda, ${ }^{18}$ traçando considerações sobre o livro $A$ exaustão da diferença, de Alberto Moreiras, propõe que "[u]m ponto de fuga

17. ÁVILA. Um passeio pelos limites da cultura, p. 159-163.

18. MIRANDA. Paisagens incertas: o latino-americanismo em tempos globais, p. 27-31. 
possível parece esboçar-se na posição, já adiantada aqui, de estar dentro e fora da representação latino-americana", ${ }^{19}$ o que implicaria em reconhecer que "as condições de possibilidade do latino-americanismo são ao mesmo tempo suas condições de impossibilidade, isto é, as condições que regulam o conhecimento latino-americanista também, e simultaneamente, regulam as condições de seu nãoconhecimento. ${ }^{20}$ Como essa postura - que corresponde, lembra Miranda, quase a um colapso epistêmico - pode ser traduzida em uma prática, pode parecer um enigma de difícil solução. No entanto, se abrirmos os olhos e ouvidos a uma série de agências de caráter contingencial, de onde se originam discursos parciais, precários e provisórios no dia a dia das culturas geograficamente compreendidas pelo continente americano, veremos que o elaboração crítica nascida na academia tem aí uma fonte de renovação e revitalização que não vem sendo devidamente aproveitada.

Em meu livro O retrato na rua, procurei apresentar e apreciar alguns discursos fragmentários e contingentes cuja circulação hoje não se restringe mais à rua e ao confinamento local/regional, mas que se articulam, hibridizam e suplementam, via Internet, com outros de igual disponibilidade, sem ter como referência o ainda controlador aparato de criação e transmissão de valor que é a instituição de ensino, em todos os seus níveis. O reconhecimento dessas vozes diagonais dependerá, por parte daqueles que se propõem a pensar a cultura, de um abandono - ou suspensão estratégica - de conceitos como permanência, coerência (um grande bastião de nossa crítica, desde sempre) e autenticidade, em prol da efemeridade, do nonsense e do simulacro.

Como ainda postular posições teóricas a partir de terreno tão movediço não é questão que nos deva paralisar, mas estimular e afiar nosso senso crítico.

19. MIRANDA. Paisagens incertas: o latino-americanismo em tempos globais, p. 30 .

20. MIRANDA. Paisagens incertas: o latino-americanismo em tempos globais, p. 31. 


\section{Latin American discourse positions}

Abstract: This article reviews concepts like hybridism, in-betweenness and double consciousness, elaborating on their effects and effectiveness in the Latin-American discourse.

Keywords: Latin-americanism, Silviano Santiago, Alberto Moreiras.

$$
\text { Referências }
$$

ÁVILA, Myriam. Um passeio pelos limites da cultura. In: $O$ retrato na rua: memórias e modernidade na cidade planejada. Belo Horizonte: Ed. UFMG, 2008. p. $159-163$.

BURKE, Peter. Hibridismo cultural. Trad. Leila Souza Mendes. São Leopoldo: Unisinos, 2003.

GILROY, Paul. The black Atlantic: modernity and double consciousness. Cambridge: Harvard Univ. Press, 1992.

KANT, Immanuel. Kritik der reinen Vernunft. Hamburgo: Felix Meiner Verlag, 1976.

KRISTEVA, Julia. Introdução à semanálise. Trad. Lúcia Helena França Ferraz. São Paulo: Perspectiva, 1974

MACHADO, Cassiano Elek. Hibridismo cultural de Peter Burke (24/01/04). Disponível em: <http://www.casla.com.br>. Acesso em: 20 jul. 2009.

MIRANDA, Wander Melo. Paisagens incertas: o latino-americanismo em tempos globais. Ipotesi - Revista de Estudos Literários, Universidade Federal de Juiz de Fora, v. 9, p. 27-31, 2002.

MOREIRAS, Alberto. A exaustão da diferença. Trad. Eliana L. de Lima Reis e Glaucia R. Gonçalves. Belo Horizonte: Ed. UFMG, 2001.

SANTIAGO, Silviano. Uma literatura nos trópicos. São Paulo: Perspectiva, 1978.

SPIVAK, Gayatri. Can the subaltern speak? In: NELSON, C.; GROSSBERG, L. (Ed.). Marxism and the interpretation of culture. London: Macmillan, 1988. p. 271-313. 